\title{
uMap: A Free, Open-Source Alternative to Google My Maps
}

\author{
Sepideh Shahamati (she/her) \\ Concordia University
}

sepideh.shahamati@mail.concordia.ca
Léa Denieul-Pinsky

Concordia University

lea.denieul@gmail.com
Yannick Baumann (he/him)

Université de Montréa yannick.baumann-lapierre@umontreal.ca
Sébastien Caquard

Concordia University

Since their release in 2005, Google Maps-based tools have become the de facto solutions for a variety of online cartographic projects. Their success has been accompanied by a range of critiques denouncing the individualistic market-based logic imposed by these mapping services. Alternative options to this dominant model have been released since then; uMap is one of them. uMap is a free, open-source online mapping platform that builds on OpenStreetMap to enable anyone to easily publish web maps individually or collaboratively. In this paper, we reflect on the potential and limits of uMap based on our own experiences of deploying it in six different mapping projects. Through these experiences, uMap appears particularly well-suited for collaborative mapping projects, due to its ease in connecting to remote data and its high level of interoperability with a range of other applications. On the other hand, uMap seems less relevant for crowdmapping projects, due to its lack of built-in options to manage and control public contributions. Finally, the open-source philosophy of uMap, combined with its simplicity of use and its strong collaborative capacity, make it a great option for activist mapping projects as well as for pedagogical purposes to teach a range of topics including online collaborative cartography.

KEYWORDS: uMap; open-source cartography; Google Maps; collaborative mapping; crowdmapping; activist mapping; teaching online cartography

\section{INTRODUCTION}

Since THE Release of Google Maps in 2005, the world of collaborative online cartography has changed radically. Any savvy Internet user can now set up a simple mapping platform, add placemarks, and invite contributors to participate by adding points, data, images, video, and text. These possibilities have dramatically modified the way spatial information is both produced and accessed. Collaborative online mapping platforms, epitomized by Google My Maps (the application that enables individuals to set up their own Google Maps project), have been praised for their capacity to support participatory democracy (Miller 2006; Haklay, Singleton, and Parker 2008; Warf and Sui 2010; Quinn and Yapa 2016), as well as criticized for reproducing and reinforcing existing racial, cultural, economic, technological, and digital divides (Crutcher and Zook 2009; Graham and Zook 2011;
Blaschke et al. 2012). As Palmer puts it (2014, 347), there is a fundamental contradiction between the collaborative potential of Google Maps and its individualistic, market-based logic, which has led it to develop a map interface "that has been emptied of difference, contestation, and political action." Other collaborative mapping platforms have been released over the years to provide alternatives to the dominant Google mapping model. In this paper, we look carefully at the possibilities offered by one of these platforms: uMap.

Our interest in uMap started in 2017, when Nelly Markovsky, an undergraduate student at Concordia University, was asked by the Regional Program for the Settlement and Integration of Asylum Seekers (PRAIDA) in Québec to produce a collaborative online map of 
services offered to asylum seekers in Montréal (Markovsky 2017). This online map was envisioned as a digital entry point for asylum seekers looking for services provided by different organizations across the city. Markovsky defined a set of criteria to select the relevant online mapping platform: (1) free or cheap; (2) easy to use for the end-user (i.e., asylum seekers); (3) easy to update and to maintain over time by different people/organizations without any mapping software expertise; and (4) open-source to remain as close as possible to the community-based philosophy of the project. Six online mapping applications were compared for this project at the time: Mapbox, Carto, Google My Maps, MangoMap, Zeemaps, and uMap. uMap was selected to produce "The Map of Services for Refugees and Asylum Seekers in Montréal" (see Figure 1) because it best suited these criteria (Markovsky 2017). We worked with Markovsky on the PRAIDA project, and the overall positive experience of using uMap led us to deploy it for three other collaborative mapping projects as well as in two university courses.

Through using uMap in these six different projects, we began to identify its strengths and limits in different contexts and to reflect on its potential for different types of online mapping projects. These experiences led us to identify and describe three main domains in which uMap could be an interesting alternative to Google Maps: collaborative mapping, crowdmapping, and teaching online cartography. Before introducing uMap in general terms and discussing its pros and cons within these domains, it is important to mention that none of the authors of this paper have any connections with the uMap project.

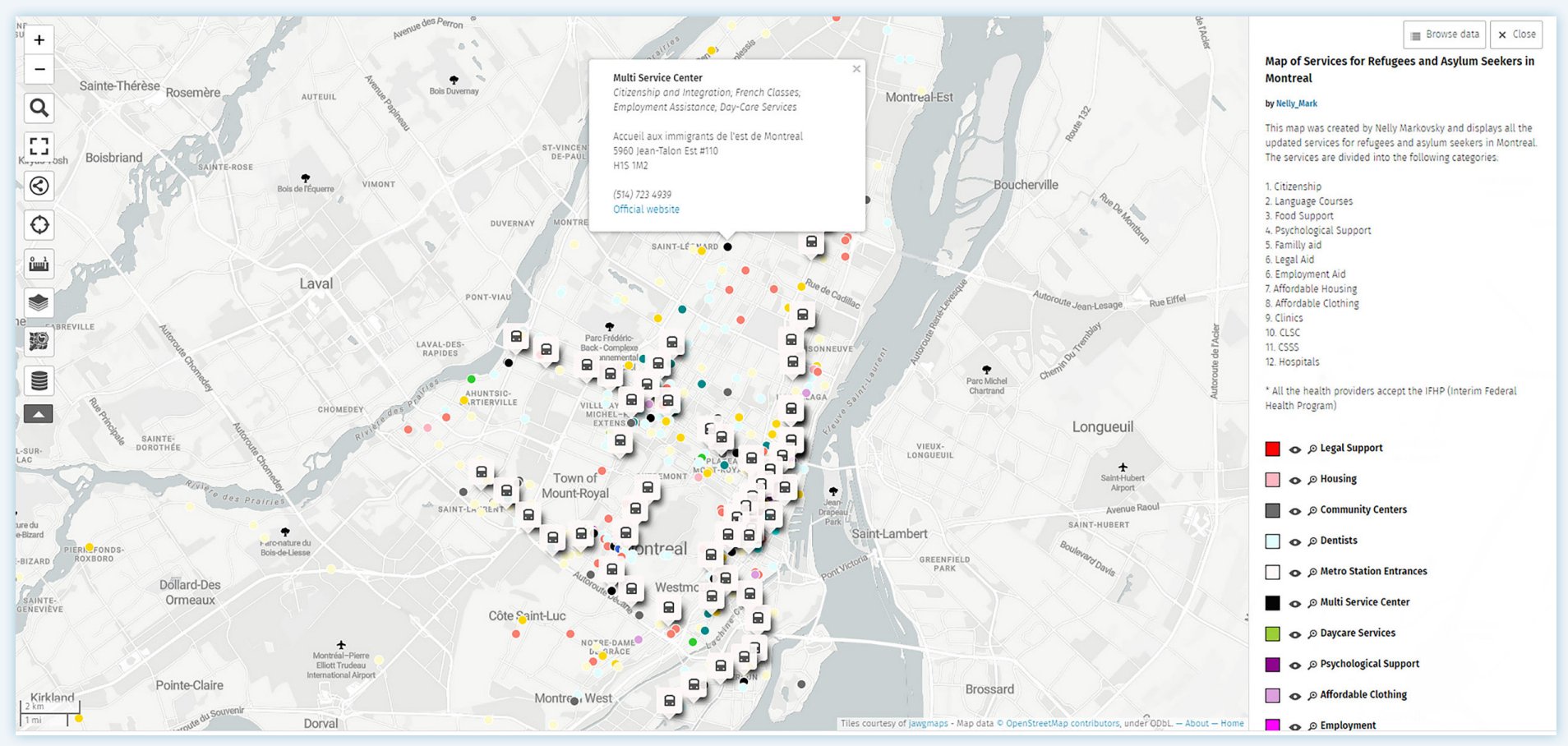

Figure 1. Map of services offered to asylum seekers in Montréal, created by Nelly Markovsky. Interactive version available at u.osmfr. $\mathrm{org} / \mathrm{m} / 132406$.

\section{WHAT IS UMAP?}

LAUNCHED IN 20I3, uMap is a free/libre and opensource software (FLOSS/FOSS) platform offering an entirely web-based environment for interactive, multimedia mapmaking and publishing. The platform is built with the JavaScript web mapping library Leaflet and the Python web app infrastructure Django. uMap is primarily developed and managed by OpenStreetMap France, a non-profit organization that acts as a local, independent chapter of the UK-based OSM Foundation. uMap's source code is available on GitHub (github.com/ umap-project/umap), enabling members to collaborate on its development or make suggestions for future updates. 
The project is covered by the permissive WTFPL license, which makes the source code into free software for redistribution and modification. It can thus be freely accessed, downloaded, or modified to customize the application based on particular needs.

At a practical level, uMap is relatively simple to use. It allows users to quickly develop a map with points of interest and popup windows that can include text, images, and video. Existing geolocated data can also be imported in a variety of formats (e.g., geojson, osm, csv, gpx, kml, GeoRSS). Map geometries can be organized and styled by layers of points, lines, or polygons. Once finished, the map can then be shared on the web via a unique link or embedding into HTML using an iframe. The platform also allows users to import geotagged photos, create slidebased maps, and produce simple multimedia geographic tours. In this way, uMap can provide some of the basic feature characteristics of story-based map-making tools like Esri Story Maps, (formerly) Google Tour Builder, and Story Map JS (see Caquard and Dimitrovas 2017). Users can also modify data within, and export data from, uMap, making the platform interoperable and particularly easy to integrate into other workflows. The application manages data internally using GeoDjango, but can also map data managed by remote, third-party databases such as Google Sheets and Zoho Sheets.

Overall, uMap offers capabilities comparable to Google My Maps. The reasons usually emphasized by those opting to use the former over the latter are its richness in features, ease of implementation, and open-source philosophy (see for instance, Law and Ramos 2017; Rönneberg, Laakso, and Sarjakoski 2019). These advantages have led to the platform being used in numerous contexts, such as activism, community mapping, and risk management. Since its launch in 2013, uMap has remained free and open-source, while many other online mapping applications that may have begun as open-source and/or free tools have since moved toward for-profit business models by implementing enterprise pricing plans and limiting free services. These limitations can occur in many ways, whether by restricting data imports and exports (e.g., Scribblemaps), strictly limiting the number of views or visits a map can receive (e.g., Zeemaps, MangoMap), terminating the account after a given timespan (e.g., Carto), or imposing a watermark on all base maps (e.g., iMapBuilder). uMap stands out in its ongoing commitment to FOSS despite an increasing marketization of online mapping services in the previous decade.

The commercialization of other previously free online mapping applications brings into question the sustainability of FOSS tools such as uMap. Just like many other open-source software projects, $99 \%$ of uMap is developed by volunteers, according to its main developer, Yohan Boniface (personal communication with authors). Under the open-source model, a project is initially developed by a project "leader" and is maintained over time by volunteer contributors who, depending on their knowledge, "design, test, write, debug, distribute, and document" the project (von Krogh and Spaeth 2007, 237). Although this approach (like many others) does not guarantee sustainability of the software over time, which is a major drawback for the adoption for long-term projects, our experience with uMap reaffirms that "open source ... has become robustly self-sustaining" (Asay 2013, 1). Indeed, all the maps we have produced so far with uMap since 2017 are still working without being maintained.

\section{UMAP IN PRACTICE}

BetweEn 2017 AND 202I, we deployed instances of uMap for four different mapping projects: (1) to produce a collaborative online map of services offered to asylum seekers in Montréal in collaboration with PRAIDA (Markovsky 2017); (2) to map sustainable resources offered to people living in Montréal, focusing on food security and community care; (3) to contribute to an anti-eviction project in the Parc-Extension neighborhood of Montréal; and (4) to collect and map circus-related stories from

members of the international circus community, including stories related to how this community was impacted by the COVID-19 pandemic. We also used uMap for pedagogical purposes in two different university undergraduate classes: (5) one class dedicated to the Geoweb, which employed uMap to map Indigenous services in Montréal in collaboration with the municipality's Commissioner of Indigenous Relations; and (6) one human geography field course in Parc-Extension that included a community 
mapping exercise (i.e., a mapathon) to map services available in the neighborhood.

These different projects all shared a common interest in using alternative online mapping technologies, a sensibility toward the open-source model, and a scarcity of financial resources. Beyond these commonalities, they were driven by different goals, such as serving the community, supporting activist campaigns, and collecting data for research as well as pedagogical purposes. Each of the authors of this paper has been in charge of implementing at least one of these online mapping projects in collaboration with a community or a group of individuals seeking support to deploy an online cartographic solution for their projects. Throughout a series of meetings and discussions with these individuals and communities, and through a series of reflective meetings among ourselves, we were able to identify the key possibilities and limitations of uMap in these particular contexts, and to reflect on the potential of uMap at a broader level. We have identified four domains in which uMap offers an interesting option, which we will further discuss in this section: (1) data management in the context of collaborative mapping; (2) data privacy in the context of activist mapping; (3) contributor management in the context of crowdmapping; and (4) open-source philosophy in the context of teaching online collaborative mapping.

\section{COLLABORATIVE MAPPING AND DATA MANAGEMENT}

Online collaborative mapping, or geocollaboration, enables different users to work on the same map either simultaneously (synchronously) or at different moments (asynchronously), by generating annotations that are "anchored to geographic locations on map-based displays" (Hopfer and MacEachren 2007, 924). Online collaborative maps provide opportunities for people to view, edit, and co-create geodatabases and their cartographic representations to address a range of issues such as disaster management (Meier 2011; Poiani et al. 2016), humanitarian work (Schörghofer et al. 2017; Gutiérrez 2018), and community engagement (Craig, Harris, and Weiner 2002).

In two of our four mapping projects (services offered to asylum seekers in Montréal and sustainable resources offered to residents of Montréal), uMap was chosen because of its particular appeal for collaborative mapping, given its ability to support different data formats and to map data stored in a variety of online data management systems (including third-party remote databases such as Google Sheets and Zoho Sheets). This flexibility is powerful for collaborative mapping projects, since it enables the plotting of different databases, managed by different collaborators, on a single map. Although these data need to follow strict standards to be mapped properly (e.g., they need to include geographic coordinates), they can all be maintained and managed independently by different groups and organizations according to their criteria and resources. This was one of the most important features for the PRAIDA project, since this project aimed to map services available for asylum seekers that were managed and maintained by different organizations. Instead of centralizing all these data into one common database, the data were organized in different spreadsheets in Zoho Sheets, each under the control of the organization that produced them (Markovsky 2017).

The capacity to call data on the fly from third-party data management services can also simplify the process of geocoding (turning addresses or placenames into geographic coordinates that can then be plotted on a map), which may otherwise be complicated for geospatial amateurs. Although uMap does not offer a geocoding option per se, it can map data from spreadsheets that do offer this service, such as Google Sheets. For instance, Google Sheets was used with uMap to geolocate and map the 270 addresses of sustainable resources collected as part of the sustainable resource map of Montréal (see Figure 2). It was also used to collaboratively geolocate and map the addresses of Indigenous services in the context of the Geoweb course (see below). For mapping projects that start with a list of addresses, Google Sheets offers an excellent geocoding option since it is free and simple to use.

However, relying on third-party proprietary data management systems such as Google Sheets has a major drawback, in that it renders a uMap project no longer completely open-source, and can be inappropriate for projects that involve sensitive data (see below). Another drawback is that Google, just like any other online service (including open-source services) can decide unilaterally to stop providing a service or to start charging for a service that was previously provided for at no cost. For instance, Google began requiring valid credit card information from every user of its Maps API in July 2018 (Griffiths 2018), and would otherwise display the text "For Development Only" on map tiles. One consequence of Google's new approach 


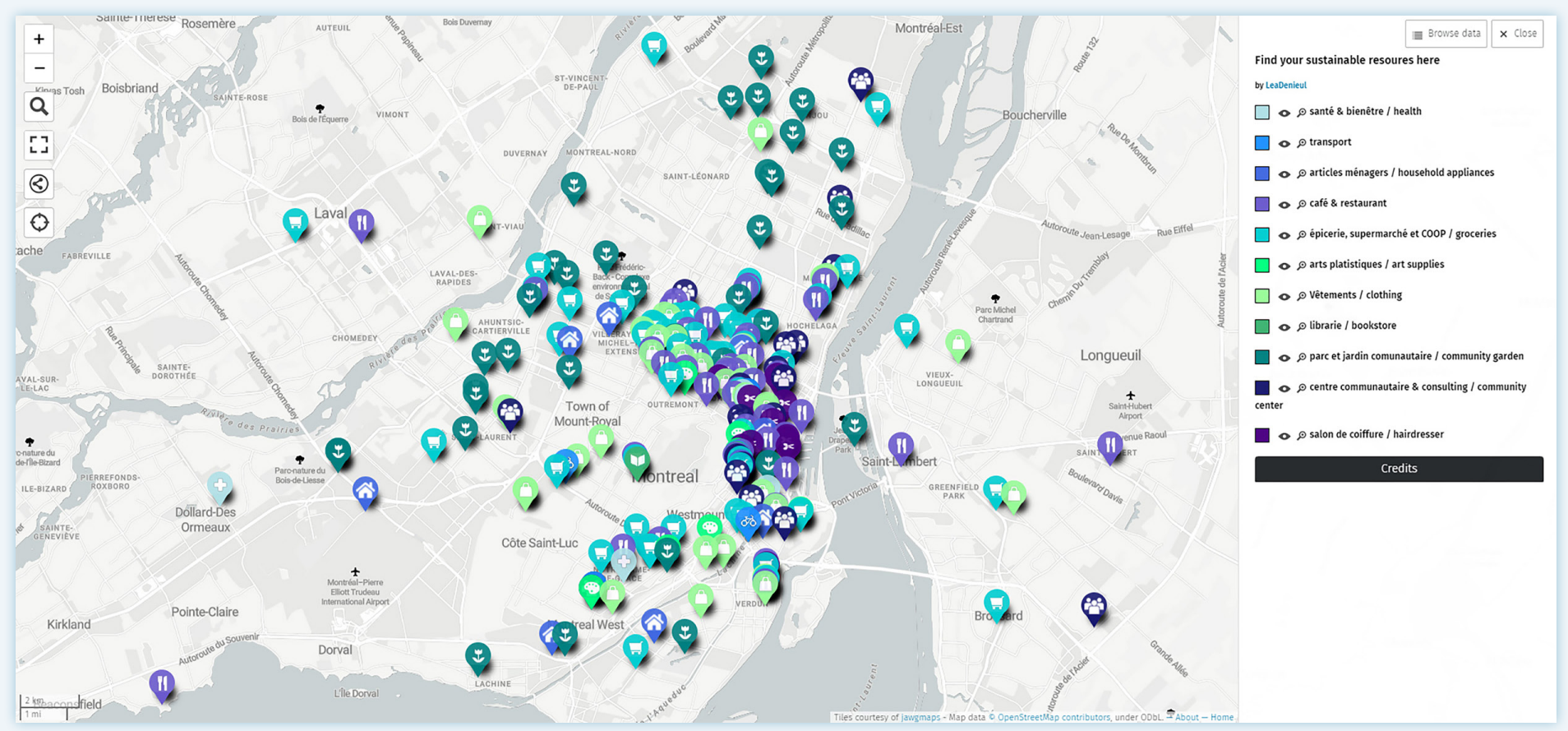

Figure 2. Map of Sustainable Resources around Montréal, created by Léa Denieul-Pinsky. Interactive version available at u.osmfr. org $/ \mathrm{m} / 556410$.

was to incite some users to start looking for alternative online mapping options such as uMap.

Overall, our experiences of mobilizing uMap for collaborative mapping projects has shown us that there is a balance to be found between proprietary tools that are freely available and easy to use (e.g., Google Sheets) and platforms that benefit from the attributes of FOSS. For some of our mapping projects, Google Sheets was an asset due to its power and convenience, while for others it was an issue because of Google's terms and conditions related to data privacy, which we discuss further in the next section.

\section{DATA PRIVACY AND ACTIVIST MAPPING PROJECTS}

Although open-source software does not guarantee user privacy (such as by encryption), it guarantees the transparency of the entire infrastructure as well as the application of certain privacy policies (Hansen, Köhntopp, and Pfitzmann 2002; Swanlund and Schuurman 2019). On the other hand, proprietary applications that offer free services often reserve the right to use the data that are managed through these services. For instance, Google's Terms of Service make it clear that although "you retain any intellectual property rights that you have in your content," Google can "host, reproduce, distribute, communicate, and use your content" at will (Google Privacy \& Terms
2021). This right to use your content for other purposes may not be an issue for projects that deal with public data, but it might be a major issue for projects dealing with sensitive information. This was the case of the Parc-Extension Anti-Eviction Mapping Project (PEAMP).

Parc-Extension, one of the most economically marginalized and ethnically diverse neighborhoods in Montréal and in Canada, has witnessed an unprecedented rise in evictions in recent years (Nicholas et al. 2019). Land speculation and housing struggles have become a major cause of concern for community groups in the neighborhood. To address these concerns, an anti-eviction mapping project was initiated in 2019 to advocate directly for housing rights in this area. This activist mapping project was inspired by the Anti-Eviction Mapping Project initiated in 2013 in San Francisco as a response to the growing human impacts of neoliberal politics and real estate speculation (Maharawel and McElroy 2018). This type of activist mapping project aims to make the landscapes of dispossession, struggle, and resistance visible (Maharawal and McElroy 2018; D'Ignazio and Klein 2020), and to stimulate reclaiming actions by consolidating solidarity and political collectivity among participants and citizens (Parker 2006).

The goal of the Parc-Extension Anti-Eviction Mapping Project was to cartographically represent recent housing 
struggles, eviction narratives, and efforts carried out by community groups to defend their housing rights. Two sources of data were used for this project. One set was obtained from the Parc-Extension Action Committee (CAPE), our partner tenant association, and drew on tenants' dossiers. The other was provided by a team of researchers, community organizers, and activists using interviews and surveys. Data privacy and an open-source philosophy were the main criteria that led us to select uMap for this project.

Part of this project's data was coming from tenants' reports to CAPE regarding their evictions and cases of landlord abuses. To make sure that we protected the confidentiality of these residents, two major tradeoffs were made: (1) the location of the points shown in the public map could not be in the exact location of where the eviction took place; and (2) we had to eschew any applications that might retain the right to use the data stored on their servers (e.g., Google), or that might be accessible by government authorities (e.g., data on USA-based servers can be accessed by US federal authorities). The main instance of uMap (umap.openstreetmap.fr) is managed by OpenStreetMap France, which uses servers hosted by OVH in Roubaix, France. Thus, data in uMap falls legally under the European Union General Data Protection Regulation (GDPR), which is more restrictive in terms of access than the US legal context (Pernot-LePlay 2020). Although it is clear that the lack of data encryption does not prevent illegal access to such data, its storage in European servers makes legal access more complex than in US servers.

The Parc-Extension Anti-Eviction Mapping Project resulted in two maps: (1) eviction struggles of ParcExtension residents, and (2) community assets in ParcExtension. Both maps are available in two versions for privacy reasons: one includes all the data and is password protected and only accessible by the members of PEAMP and CAPE for internal purposes, and the second one includes a selection of data and is made available to the public through PEAMP's website (Figure 3).

\section{UMAP FOR CROWDMAPPING}

Online collaborative mapping can range from a simple project involving a couple of individuals working collaboratively on the same database, up to a vast, complex project that enables anyone to contribute geolocated data through different means such as clickable maps, text messages, or online forms. The latter is often called crowdmapping.

A crowdmapping project is potentially open to everyone (i.e., the crowd) to contribute. The potential (and limitation) of crowdmapping was first revealed in the context of major crises such as the 2005 aftermath of Hurricane Katrina in New Orleans (Miller 2006) and of the 2011 earthquake

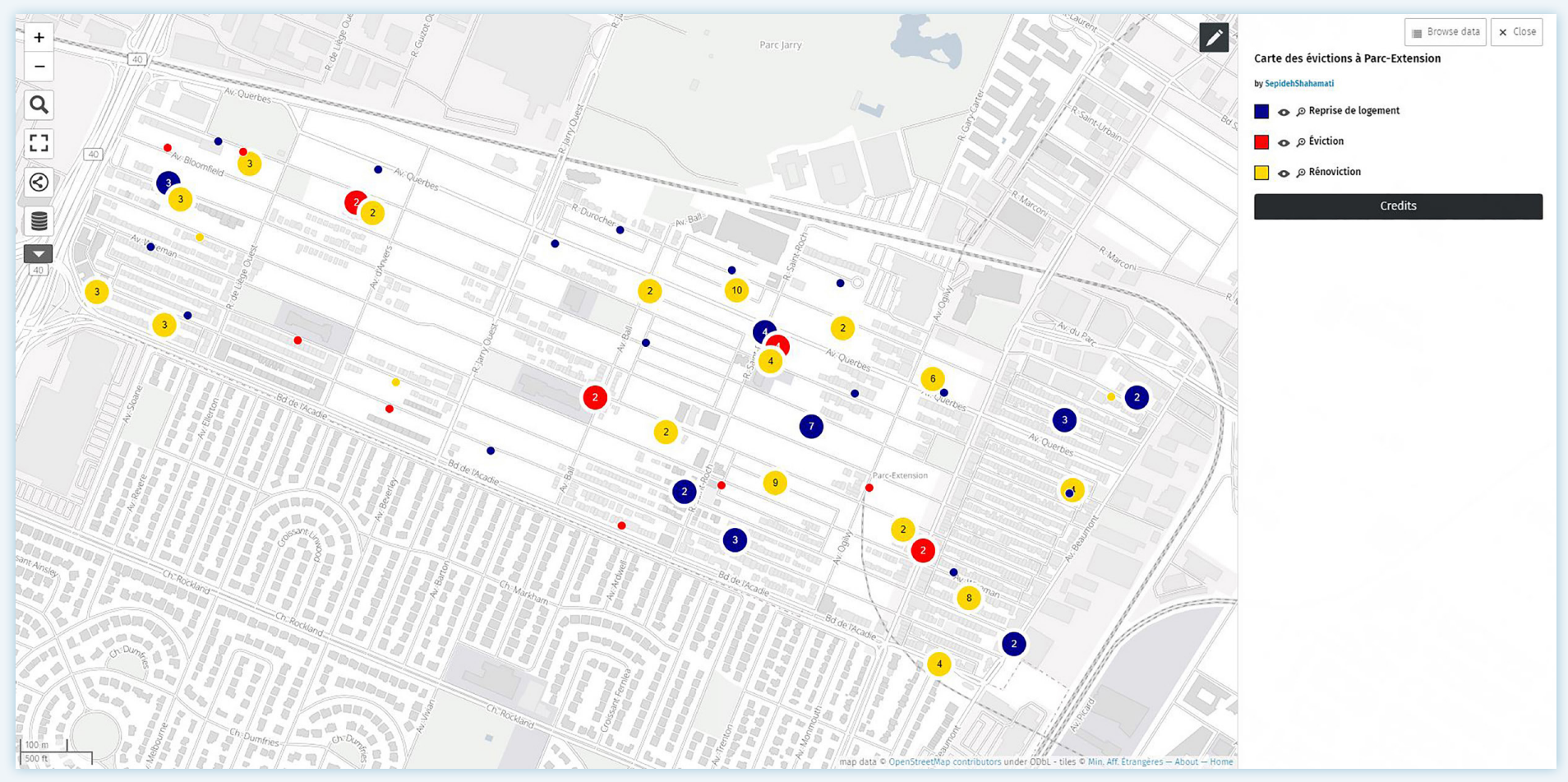

Figure 3. Eviction map of Parc-Extension by PEAMP. Full credits and interactive version available at u.osmfr.org/m/641974. 
in Haiti (Zook et al. 2010; Meier 2011). Ushahidi, originally released in 2008 to monitor post-election violence in Kenya, was one of the first open-source crowdmapping platforms to become widely used (Okolloh 2009). While Ushahidi remains a powerful crowdmapping platform, it was also quite complex to run without technical support. To address this issue, Ushahidi released Crowdmap in 2010, a web application which aimed to make crowdmapping easier and more accessible (Ushahidi Staff 2015). However, it was shut down in 2021 due to insufficient resources to maintain it (Hinga 2020). Crowdspot is yet another crowdmapping platform, originally launched in 2015 to help the city of Melbourne become bike-friendly (Aisenberg 2016). Today, Crowdspot appears to be an interesting alternative to Ushahidi to set up crowdmapping projects (see for instance Tanner et al. 2020), but it is neither open-source nor free. Other JavaScript-based webmapping libraries such as Mapbox, Leaflet, OpenLayers and even Google's Maps API have been mobilized by more tech-savvy individuals to design one-off online mapping applications with crowdmapping functions such as the Queering the Map project (LaRochelle 2020; Kirby et al. 2021). However, tailoring these applications often requires a certain level of technological expertise that makes them inappropriate for crowdmapping projects with low budgets and limited technological resources.

uMap offers one basic crowdmapping function, which is to give anyone the option to edit the map once they have the link. This openness is fully aligned with the opensource philosophy which, according to the OSM founder Steve Coast, "is key to putting as few barriers as possible between mallets and the map" (Coast 2011, 4). However, the options available to any anonymous public user are too powerful for most use-cases: most creators who make their maps public may want the public's contributions (e.g., adding new map markers), but don't want the public to be able to remove existing markers, modify data, edit a map's user interface or even to update user permissions. This feature could increase the risk of the map being hacked, which can actually have some positive consequences (McConchie 2015), but can also be highly damaging to a crowdmapping project. The Queering the Map project faced this very problem when it was hacked by Donald Trump's supporters on February 11, 2018 (LaRochelle 2020).

With uMap, this risk can be reduced by using a third-party survey questionnaire service to collect data, which we did with The World Circus and Stories Mapping project. This was an academic project developed at Concordia University under the direction of professor Patrick Leroux, for which uMap was used in combination with ArcGIS Survey123. It was conceived in collaboration with researchers studying contemporary circuses with two main objectives in mind: (1) to provide a virtual space for members of the international circus community to express their feelings about the impact of COVID-19 on their professional and personal lives; and (2) to collect oral and unwritten stories about contemporary and historical circus sites and venues for research purposes. This project ended up being more complex than originally expected. It required:

- a rigorous and lengthy process for ethics clearance, as it was a university-supported project;

- the design of a 10-question survey to collect the stories using ArcGIS Survey123;

- the preparation of the ethics agreement and the survey in five languages (French, English, Spanish, Brazilian Portuguese, and Simplified Chinese) to reach out to a large proportion of the circus community worldwide;

- a combination of "flows" available in the Power App library of Microsoft Office 365 to direct each submission to a moderator fluent in the language used by the storyteller; and finally

- another combination of data flows to transfer the data from Survey123 to Google Sheets, which could then be used to update the uMap automatically.

This crowdmapping project mobilized quite a bit of effort in terms of ethics, survey development, data flow management, translation, and moderation, without providing the expected results: only 27 stories have been mapped so far, and most of these stories were submitted within a couple of weeks of the project's launch in July 2020 during active promotion of the project (see Figure 4).

Reflecting on this experience led us to articulate three drawbacks of crowdmapping in general and crowdmapping with uMap in particular. First, crowdmapping projects, just like any collaborative mapping project, require ongoing attention: they are living entities that need regular maintenance, promotion, and updates in order to grow and evolve. The World Circus and Stories Mapping Project is emblematic of challenges faced by many crowdmapping and collaborative online mapping projects where 

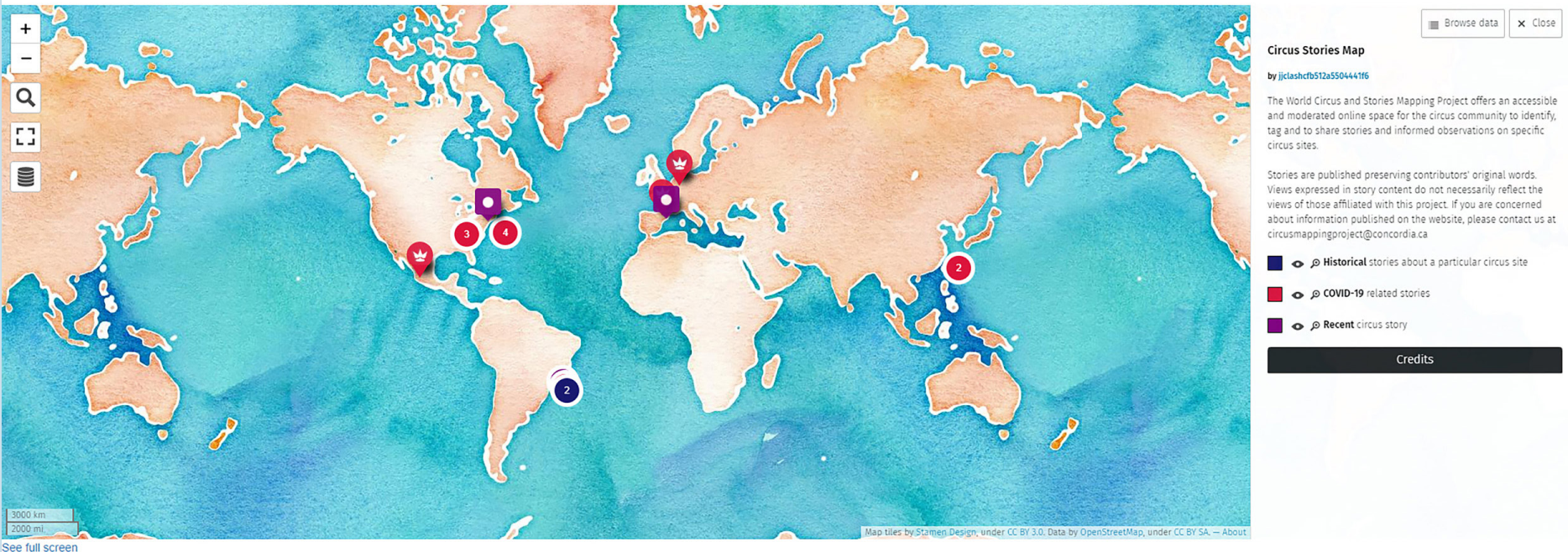

Figure 4. Screen capture of The World Circus and Stories Mapping Project. Full credits and interactive version available at geomedialab. org/circusmap.html.

a lot of energy, time, and resources were spent on setup, but not enough was budgeted to maintain and grow it over time. Second, the openness of uMap exposes crowdmapping projects to any kind of contribution, which can be challenging in cases of cartographic vandalism (Ballatore 2014) as well as inappropriate for a research project operating under a strict ethical protocol. This led us to deploy a third-party application (ArcGIS Survey123) to control and oversee each contribution. However, this made the process of contributing more convoluted than what would be ideal to appeal to a large audience (i.e., the crowd). Here we can see a clear tension between the ethics and data required by the research agenda and the simplicity required to attract a large number of individual contributors. Finally, it is important to mention once more that relying on third-party survey questionnaire services for data collection raises the question of data privacy. Although this was not a central issue in the context of The World Circus and Stories Mapping Project since all the stories were intended for the public, this crowdmapping infrastructure would not have been appropriate for the Parc-Extension Anti-Eviction Mapping Project as discussed previously, since the data were stored using two different pieces of proprietary software (ArcGIS Survey123 and Google Spreadsheets) and transferred via a third one (Power App library of Microsoft Office 365). Indeed, a fully opensource crowdmapping project with uMap could be possible, but might require constant monitoring to ensure that the new contributions are appropriate and that previous contributions are not altered (voluntarily or involuntarily).

\section{UMAP IN AND OUT OF THE CLASSROOM}

The last domain in which we deployed uMap was pedagogical. Geospatial education has been (and still is) dominated in the Western world by Esri and its suite of proprietary software such as ArcView, ArcMap, and ArcGIS Pro/Online. However, the success of Google's products in the first decade of the twenty-first century has shaken the foundations of Esri's dominance, particularly in academia (Joliveau et al. 2018). Although university teachers and departments have remained largely faithful to Esri products and standards, they have also opened their classrooms and labs to Google Maps/Earth as well as to open-source applications such as QGIS. This diversification of geospatial tools in education has been accompanied by students' growing exposure to critical GIS theories that deconstruct and reveal the power structure, political economy, and cultural norms imposed by geospatial industry standards (Elwood and Wilson 2017; Gieseking 2018). This illustrates a major point of tension in geospatial education: preparing students for professional practice, while encouraging them to change it fundamentally. In this context, we have chosen uMap because it is a relevant pedagogical tool to touch on these two domains, and it expands the online mapping options currently available to teachers and 
students. Since 2018, we have replaced Google Maps with uMap to teach online collaborative mapping practices and concepts in an undergraduate course entitled "Geomedia and the Geoweb" at Concordia University. We also used uMap in the 2019 version of a human geography field course at Université de Montréal to organize a mapathon to collaboratively map community services in the ParcExtension neighborhood in Montréal (see Figure 5).

In practical terms, teaching online collaborative mapping with uMap requires introducing students to the entire mapping pipeline, from data collection to map publication. While simple to use and easy to grasp for most of the students, uMap also provides enough options for more adventurous students interested in exploring symbology customization and data management (e.g., data flow process, data control, remote database management, and security access).

In the 2019 version of the class "Geomedia and the Geoweb," we asked students to collaboratively enter a list of addresses of services potentially relevant for Indigenous people in Montréal into Google Sheets, in order to geocode them and then to map them with uMap. This exercise was developed in collaboration with the Commissioner of Indigenous Relations at the City of Montréal, who provided us with public data they wanted to be mapped. Students were also asked to explore the symbology used to represent this data and to design a web page in which to embed the map and contextualize it for a broad audience. One of the maps designed by the students was selected and presented during a showcase event organized in collaboration between Concordia University and the City of Montréal and was given to representatives of the municipality along with the necessary credentials to modify and maintain it over time (see Figure 6).
Students were then invited to reflect on whether the map was accessible by the individuals who could benefit from these services, and to propose concepts to make it available offline to members of Indigenous communities living in Montréal. Students developed a range of creative solutions, such as printed poster maps to display in bus shelters, and painted maps of nearby services on sidewalks or as murals. This activity helped to make students more aware of certain limitations of online mapping options such as accessibility, searchability, language restrictions and cultural disconnection. It resonated with the necessity of inviting students to become more aware of the ways that socio-technological shifts embodied and supported by online mapping applications "condition knowledge, knowing, power, and impact" (Elwood and Wilson 2017, 2102).

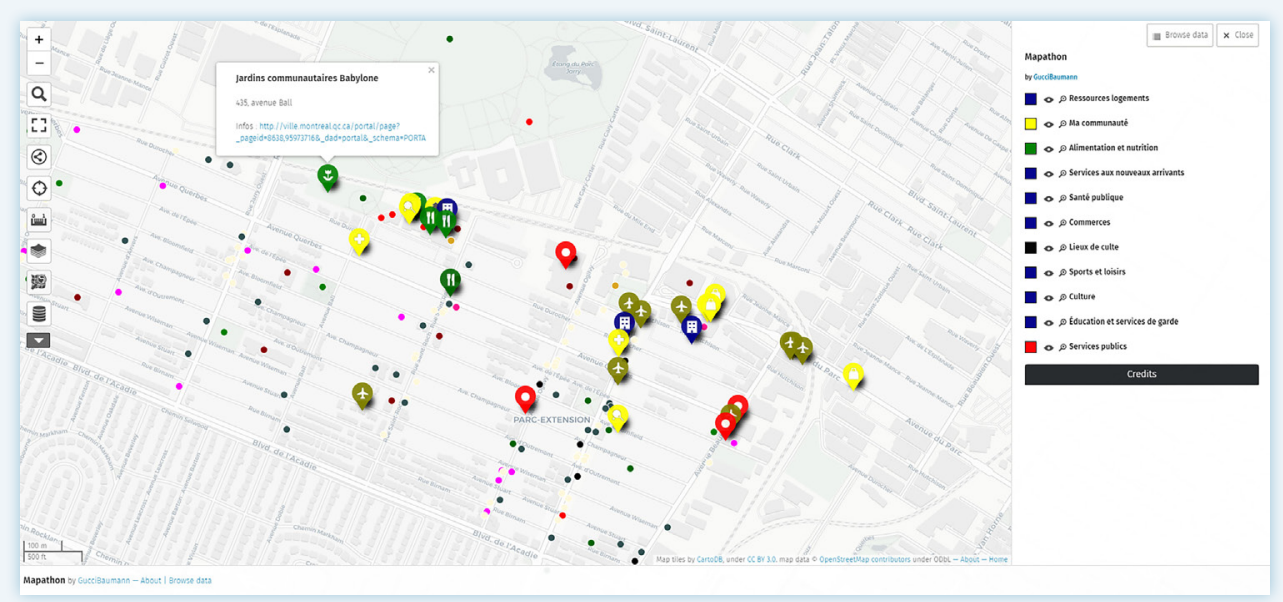

Figure 5. Screen capture of the collaborative map of services available in the ParcExtension neighborhood, compiled during a field course in human geography. Designed by Yannick Baumann. Interactive version available at u.osmfr.org/m/356298.

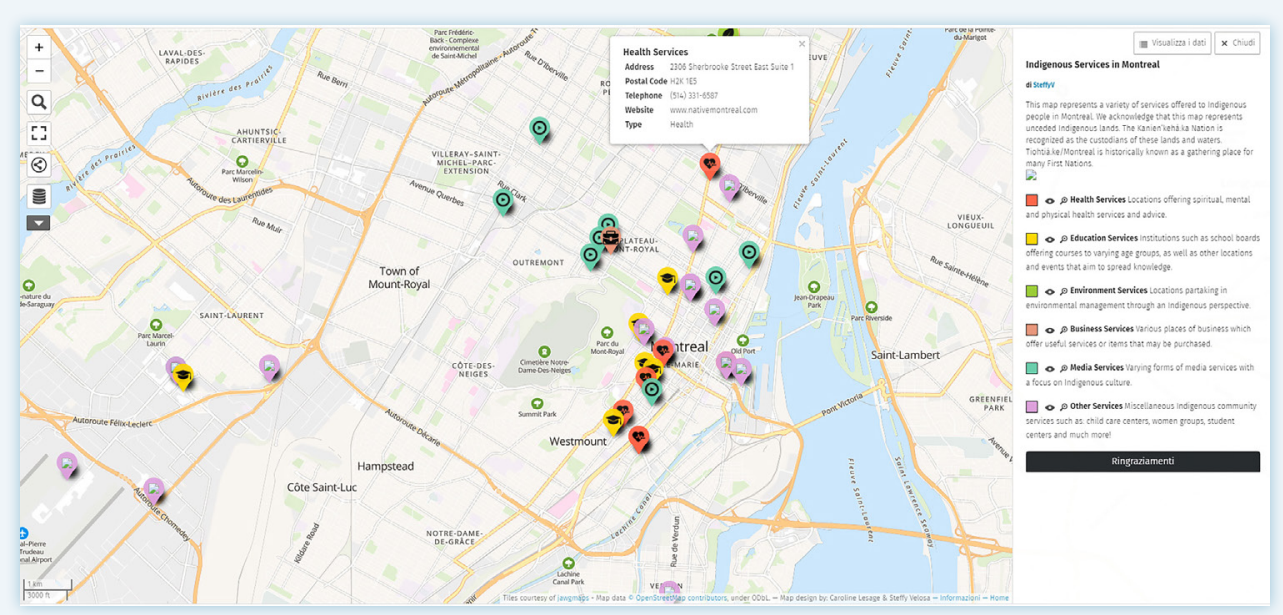

Figure 6. Screen capture of the collaborative map of Indigenous services offered throughout the city of Montréal. Designed by Caroline Lesage \& Steffy Velosa. Interactive version available at: u.osmfr.org $/ \mathrm{m} / 382794$. 
It led to engaging discussions about the pros and cons between proprietary / for-profit applications such as Google Maps and FOSS applications such as uMap in this broader socio-technological context.

Working with FOSS such as uMap offers a relevant environment to discuss the more conceptual aspects of online mapping, which most undergraduate students are not familiar with: namely, the value and the limits of collaborative software development, the ethics of data ownership and data sharing, and the influence of dominant corporate mapping tools on our ways of envisioning the world.
Using uMap in the classroom becomes an invitation to not only use mapping tools, but to reflect on mapping practices and their implications. The open-source philosophy of uMap, combined with its simplicity of use, collaborative dimension, and reliability, makes it a great candidate to address pedagogical challenges raised by teaching critical GIScience. Approaching maps "as a form of social engagement" (Elwood and Wilson 2017, 2108) requires looking beyond the map's surface and interface to dissect and scrutinize its multiple components. In this way, the entire mapping apparatus, agency, intentions, and potential consequences become more tangible and understandable.

\section{CONCLUSION}

uMap is a Simple bUt VERSATile free/libre opensource online mapping application that complements the open-source geospatial family by offering a compelling alternative to Google (My) Maps. Drawing on our own experiences of using uMap in six different contexts, we found it particularly well-suited for deploying and maintaining collaborative online mapping projects, suggesting that $\mathrm{uMap}$ is a solid FOSS alternative to the dominant for-profit mapping model. For people and organizations working remotely with different datasets on a shared map, uMap offers valuable options such as its ease in connecting remote data and its high level of interoperability with a range of other applications. For activist mapping projects, uMap offers an alternative model to dominant systems and worldviews. Its open-source model supports the idea of data sharing and collaborative knowledge production for the common good, as well as some level of data privacy and data control. The simplicity of using uMap, its collaborative capacity and its open-source philosophy, make it a great option to use in teaching mapping practices and concepts associated to online collaborative mapping.

Obviously uMap is far from perfect. Its cartographic design options are limited (e.g., no proportional symbol options), and it lacks refined, built-in options to control contributions, which makes it challenging to use for crowdmapping projects. Another issue that we identified throughout these projects was the lack of engagement and ownership that the different partners demonstrated towards the maps themselves. Although projects carried out with PRAIDA, the City of Montréal, or circus researchers were designed with the intention of transferring oversight to them for ongoing maintenance and data collection, none of these collaborators have since appropriated these tools. This probably speaks to the gap that might remain between mapmakers (i.e., us) that see uMap as a simple tool to operate and users that might not have the time, resources, or the interest to maintain a project over time. Such issues of maintenance and ownership are not new and extend beyond collaborative work on uMap to broader discussions that aim to make mapping processes with community partners more participatory (for instance see Johnson et al. 2015). uMap is thus a great tool for collaborative mapping projects as long as data providers are committed to updating the data and maintaining the map over time.

Overall, uMap offers an open-source and feature-rich alternative to dominant proprietary online mapping applications. Like Gieseking (2018) and Pavlovskaya (2018), we believe that researchers, teachers, community workers, and activists should be responsible when choosing mapping software to use in their respective projects. The use and promotion of free, open-source systems is politically important because it provides interesting alternatives for projects committed to collective knowledge production dissociated from economic incentives and resisting collecting data for purposes beyond the project at hand or tracking users. Moreover, it keeps online mapping as open as possible to projects with little financial support and technological expertise. It is for these reasons that we believe uMap should be seriously considered as an option when starting any collaborative or educational online mapping project. 


\section{REFERENCES}

Aisenberg, Anthony. 2016. "BikeSpot: Perceptions of Risk vs Real Risk.” Crowdspot Blog, July 7, 2016. https://medium.com/crowdspot-blog/bikespotperceptions-of-risk-vs-real-risk-549fde708c6f.

Asay, Matt. 2013. “Q\&A. Is Open Source Sustainable?” Technology Innovation Management Review, January 2013: 46-49.

Ballatore, Andrea. 2014. "Defacing the Map: Cartographic Vandalism in the Digital Commons." The Cartographic Journal 51 (3): 214-224. https://doi.org/10 $.1179 / 1743277414 Y .0000000085$.

Blaschke, Thomas, Karl Donert, Frank Gossette, Stefan Kienberger, Martin Marani, Salman Qureshi, and Dirk Tiede. 2012. "Virtual Globes: Serving Science and Society." Information 3 (3): 372-390. https://doi. org/10.3390/info3030372.

Caquard, Sébastien, and Stefanie Dimitrovas. 2017. "StoryMaps \& Co. The State of the Art of Online Narrative Cartography.” M@ppemonde 121: 1-31. http://mappemonde.mgm.fr/121_as1/\#englishversion.

Coast, Steve. 2011. "How OpenStreetMap is Changing the World." In Web and Wireless Geographical Information Systems, edited by Katsushi Tanaka, Peter Fröhlich, and Kyoung-Sook Kim, 4. Berlin: Springer.

Craig, William J., Trevor M. Harris, and Daniel Weiner. 2002. "Conclusion." In Community Participation and Geographic Information Systems, edited by William J. Craig, Trevor M. Harris, and Daniel Weiner, 367-372. London: Taylor \& Francis.

Crutcher, Michael, and Matthew Zook. 2009.

"Placemarks and Waterlines: Racialized Cyberscapes in Post-Katrina Google Earth." Geoforum 40 (4): 523-34. https://doi.org/10.1016/j.geoforum.2009.01.003.

D'Ignazio, Catherine, and Lauren F. Klein. 2020. Data Feminism. Cambridge, MA: The MIT Press.
Elwood, Sarah, and Matthew Wilson. 2017. "Critical GIS Pedagogies Beyond 'Week 10: Ethics.” International Journal of Geographical Information Science 31 (10): 2098-2116. https://doi.org/10.1080/13658816 .2017 .1334892 .

Gieseking, Jen Jack. 2018. "Operating Anew: Queering GIS with Good Enough Software." The Canadian Geographer 62 (1): 55-66. https://doi.org/10.1111/ cag.12397.

Google Privacy \& Terms. 2021. “Terms of Service: Permission to use your account." Accessed February 8, 2022. https://policies.google.com/terms?hl=en-US.

Graham, Mark, and Matthew Zook. 2011. "Visualizing Global Cyberscapes: Mapping User-Generated Placemarks." Journal of Urban Technology 18 (1): 115132. https://doi.org/10.1080/10630732.2011.578412.

Griffiths, Jamie. 2018. "Google Maps API Pricing Changes: What do They Mean?” Manifesto, May 9, 2018. https://manifesto.co.uk/ google-maps-api-pricing-changes.

Gutiérrez, Miren. 2018. "Maputopias: Cartographies of Communication, Coordination and Action-the Cases of Ushahidi and InfoAmazonia." GeoJournal 84: 101-120. https://doi.org/10.1007/s10708-018-9853-8.

Haklay, Muki, Alex Singleton, and Chris Parker. 2008. "Web Mapping 2.0: The Neogeography of the GeoWeb.” Geography Compass 2 (6): 2011-2039. https://doi.org/10.1111/j.1749-8198.2008.00167.x.

Hansen, Marit, Kristian Köhntopp, and Andreas Pfitzmann. 2002. "The Open Source ApproachOpportunities and Limitations with Respect to Security and Privacy." Computers E Security 21 (5): 461-471. https://doi.org/10.1016/ S0167-4048(02)00516-3.

Hinga, Cecilia 2020. "Saying Good-bye to Crowdmap.com.” Ushahidi, September 30, 2020. https://www.ushahidi.com/blog/2020/09/30/ announcing-our-v2-v3-migration-tool. 
Hopfer, Suellen, and Alan M. MacEachren. 2007. "Leveraging the Potential of Geospatial Annotations for Collaboration: a Communication Theory Perspective." International Journal of Geographical Information Science 21 (8): 921-934. https://doi. org/10.1080/13658810701377780.

Johnson, Peter, Jon Corbett, Christopher D. Gore, Pamela Robinson, Peter Allen, and Renee Sieber. 2015. "A Web of Expectations: Evolving Relationships in Community Participatory Geoweb Projects." ACME: An International Journal for Critical Geographies 14 (3): 827-848. https://www.acme-journal.org/index. php/acme/article/view/1235.

Joliveau, Thierry, Matthieu Noucher, Laurent Couderchet, Sébastien Caquard. 2018. "Enseigner le géoweb à distance par la pratique et la critique." Ingénierie des Systèmes d'Information 22 (5): 11-33. https://www.iieta.org/journals/isi/paper/10.3166/ ISI.22.5.11-33.

Kirby, Emma, Ash Watson, Brendan Churchill, Brady Robards, and Lucas LaRochelle. 2021. "Queering the Map: Stories of Love, Loss and (Be)Longing within a Digital Cartographic Archive." Media, Culture E' Society 43 (6): 1043-1060. https://doi. org/10.1177/0163443720986005.

von Krogh, Georg, and Sébastien Spaeth. 2007. "The Open Source Software Phenomenon: Characteristics that Promote Research.” The Journal of Strategic Information Systems 16 (3): 236-253. https://doi. org/10.1016/j.jsis.2007.06.001.

LaRochelle, Lucas. 2020. "Queering the Map: On Designing Digital Queer Space.” In Queer Sites in Global Contexts, edited by Regner Ramos and Sharif Mowlabocus, 133-147. London: Routledge. https:// doi.org/10.4324/9781003002338.

Law, Siew Fang, and Jose Ramos. 2017. "Participatory Knowledge Co-creation: Using Digital Mapping as an Emancipatory Method." In Emancipatory and Participatory Methodologies in Peace, Critical, and Community Psychology, edited by Mohamed Seedat, Shahnaaz Suffla, and Daniel J. Christie, 61-76. Cham, Switzerland: Springer International Publishing. https://doi.org/10.1007/978-3-319-63489-0_6.
Maharawal, Manissa M., and Erin McElroy. 2018. “The Anti-eviction Mapping Project: Counter Mapping and Oral History toward Bay Area Housing Justice." Annals of the American Association of Geographers 108 (2): 380-389. https://doi.org/10.1080/24694452.2017.13 65583.

Markovsky, Nelly. 2017. "Mapping Services for Refugees in Montréal.” Honors Thesis, Concordia University.

McConchie, Alan. 2015. "Hacker Cartography: Crowdsourced Geography, OpenStreetMap, and the Hacker Political Imaginary." ACME: An International Journal for Critical Geographies 14 (3): 874-898. https:// www.acme-journal.org/index.php/acme/article/ view/1237.

Meier, Patrick. 2011. "Changing the World, One Map at a Time." re:publica. http://www.youtube.com/ watch?v=Hh_PiVqf8BA.

Miller, Christopher C. 2006. "A Beast in the Field: The Google Maps Mashup as GIS/2." Cartographica 41 (3): 187-199. https://doi.org/10.3138/ J0L0-5301-2262-N779.

Nicholas, Naomi, Emanuel Guay, Alex Megelas, Alexandre Cadieux, Leonora Indira King, and Rose-Anne St-Paul. 2019. "Homelessness, Hardship and Public Action in Gentrifying Areas: The Case of Park Extension, Montreal." Homeless Hub Blog, April 12, 2019. https://www.homelesshub.ca/ blog/homelessness-hardship-and-public-actiongentrifying-areas-case-park-extension-montreal.

Okolloh, Ory. 2009. "Ushahidi, or 'Testimony': Web 2.0 Tools for Crowdsourcing Crisis Information.” In PLA 59 Change at Hand: Web 2.0 for Development, edited by Holly Ashley, Jon Corbett, Ben Garside, and Giacomo Rambaldi, 65-70. London: International Institute for Environment and Development.

Palmer, Lindsay. 2014. "Ushahidi at the Google Interface: Critiquing the 'Geospatial Visualization of Testimony.”' Continuum 28 (3): 342-356. https:// doi.org/10.1080/10304312.2014.893989. 
Parker, Brenda. 2006. “Constructing Community through Maps? Power and Praxis in Community Mapping." The Professional Geographer 58 (4): 470-484. https://doi.org/10.1111/j.1467-9272.2006.00583.x.

Pavlovskaya, Marianna. 2018. "Critical GIS as a Tool for Social Transformation." The Canadian Geographer 62 (1): 40-54. https://doi.org/10.1111/cag.12438.

Pernot-LePlay, Emmanuel. 2020. "EU Influence on Data Privacy Laws: Is the US Approach Converging with the EU Model?" Colorado Technology Law Journal 18 (1): 25-48.

Poiani, Thiago Henrique, Roberto Dos Santos Rocha, Lívia Castro Degrossi, and Joao Porto De Albuquerque. 2016. "Potential of Collaborative Mapping for Disaster Relief: A Case Study of OpenStreetMap in the Nepal Earthquake 2015." In Proceedings of the 49th Hawaii International Conference on System Sciences, edited by Tung X. Bui and Ralph H. Sprague, Jr., 188-197. Los Alamitos, CA: IEEE. https://doi.org/10.1109/HICSS.2016.31.

Quinn, Sterling, and Lakshman Yapa. 2016.

"OpenStreetMap and Food Security: A Case Study in the City of Philadelphia." The Professional Geographer 68 (2): 271-280. https://doi.org/10.1080/00330124 .2015.1065547.

Rönneberg, Mikko, Mari Laakso, and Tapani Sarjakoski. 2019. "Map Gretel: Social Map Service Supporting a National Mapping Agency in Data Collection.” Journal of Geographical Systems 21 (1): 43-59. https://doi. org/10.1007/s10109-018-0288-z.
Schörghofer, Richard, Stefan Lang, Lorenz Wendt, and Barbara Riedler. 2017. "CMaP-A Collaborative Mapping Platform for Humanitarian Organizations.” GI_Forum 5 (1): 207-216. http://dx.doi.org/10.1553/ giscience2017_01_s207.

Swanlund, David, and Nadine Schuurman. 2019. "Resisting Geosurveillance: A Survey of Tactics and Strategies for Spatial Privacy." Progress in Human Geography 43 (4): 596-610. https://doi. org/10.1177/0309132518772661.

Tanner, Sophie, Nicole Kalms, Hayley Cull, Gill Matthewson, and Anthony Aisenberg. 2020. "Disruption and Design: Crowdmapping Young Women's Experience in Cities.” IDS Bulletin 51 (2): 113-128. https://doi.org/10.19088/1968-2020.133.

Ushahidi Staff. 2015. "Why is it called Ushahidi and not Crowdmap?" Ushabidi, August 19, 2015. https://www.ushahidi.com/blog/2015/08/19/ why-is-it-called-ushahidi-and-not-crowdmap.

Warf, Barney, and Daniel Sui. 2010. "From GIS to Neogeography: Ontological Implications and Theories of Truth." Annals of GIS 16 (4): 197-209. https:// doi.org/10.1080/19475683.2010.539985.

Zook, Matthew, Mark Graham, Taylor Shelton, and Sean Gorman. 2010. "Volunteered Geographic Information and Crowdsourcing Disaster Relief: A Case Study of the Haitian Earthquake." World Medical E' Health Policy 2 (2): 7-33. https://doi. org/10.2202/1948-4682.1069. 